\title{
Activity of the chloroquine/hydroxychloroquine and mefloquine in front of the SARS-CoV-2
}

\begin{abstract}
Introduction: Identifying the main advances in the pharmacological and clinical management of the pandemic COVID-19 and SARS-CoV-2, the most recent and currently taking lives worldwide, is to priority of the scientific community that to date have rehearsed and joined efforts in order to respond with effective treatments that stop the progression of the viral infection and manage to recover the patient.

Objective: To document available information on the effects of the antimalarials chloroquine / hydroxychloroquine and mefloquine in severe acute respiratory syndrome, generated by SARS CoV-2, according to updates of the best scientific evidence, according to the evolution of the epidemic.

Material and Methods: Descriptive documentary study consisting of the selection and review of scientific material whose subject is COVID-19 and SARS-CoV-2 based on published evidence from bibliographic sources seeking different therapeutic options to combat the disease at the same time ace necessary preventive measures plough implemented worldwide. The databases consulted were Scopus, Head office Pubmed and Scielo.

Results: 132 articles related to the search were obtained in the first instance, of which they were filtered and prioritized by thematic relevance until 60 articles with to broad relationship were located. The largest number of articles was published between 2015 and $2020(n=26$; $43.3 \%$ ). It have been shown that the mechanism of today's SARS-CoV-2 is similar to that of SARS-CoV and MERS-CoV, in the same way; they share the symptoms shown by patients with COVID-19 such ace: fever, non-productive cough, dyspnea, myalgia, fatigue, normal or decreased white blood cell counts.

Conclusions: The activity of hydroxychloroquine and chloroquine in viruses is the same since the mechanism of action of these two molecules is identical. Given the pandemic, the use of these drugs is suggested in the management of patients with SARS CoV-2 / COVID-19 infection that have no contraindication for their use and the cardiac toxicity derived from these ace to cause of mortality should not be forgotten, due to what therapy must be individualized. The mefloquine is not recommended due to its neurotoxic effect and association with neuropsychiatric adverse reactions.
\end{abstract}

Keywords: COVID-19, SARS-CoV-2, therapeutic option and pandemic

\author{
Volume 7 Issue 4 - 2020
}

\author{
Elin Manrique Julio,' Belkis Palacio Villalba,' \\ Elías Alberto Bedoya Marrugo, ${ }^{2}$ Marlene \\ Duran Lengua ${ }^{3}$ \\ 'Toxicology and pharmacology, Unicartagena group investigation \\ Farmabac, Colombia \\ ${ }^{2}$ Investigation and teaching Technological University Foundation \\ Comfenalco, Group CIPTEC, National service of learning \\ SENA, Centre Agroempresarial and Mining Cartagena, group \\ GIBIOMAS, Colombia \\ ${ }^{3}$ Sciences biomédicas, Unicartagena group investigation \\ Farmabac, Colombia
}

Correspondence: Elin Manrique Julio,Toxicology and pharmacology, Unicartagena group investigation Farmabac, Colombia, Email emanriquej@unicartagena.edu.co

Received: June 15, 2020 | Published: July 14, 2020

\section{Introduction}

The SARS-CoV-2, was discovered in 2019 in Wuhan, province of Hubei of China and was sequencer and isolator in January of 2020. ${ }^{1}$ SARS-CoV- 2 is associated with a continuous shoot of atypical pneumonia designated Covid-19, that has affected to more than 2 millions of people and has left more than 200 one thousand died in the world to April of the 2020, enciphers that it can increase even more. On 30 January 2020, the WHO declared the public epidemic of SARS-CoV-2 like a sanitary emergency of international interest. 2,3 So much the SARS-CoV like the SARS-CoV-2 are closely related and origin Aron in bats, that probably servant like reservoirs for these two viruses, but the intermediate guest SARS-CoV-2 keeps on being unknown. ${ }^{2,4}$ Like result of the big impact generated, look for different therapeutic options to combat the illness at the same time that they implement the measures of necessary prevention all over the world. By the previous, the present review centers in the study of drugs antimalárics as they are: chloroquine/hydroxychloroquine, at present used; initiating with a review of the structure of SARS-CoV-2 and gives a look to the drug mefloquine like therapeutic option in front of the pandemic.

\section{Material and methods}

Descriptive study is the consistent documentary in the selection and review of scientific material whose subject is COVID-19 and SARS-Cov-2 with bibliographic sources that look for different therapeutic options to combat the illness and warn all over the world. The databases consulted were Scopus, Pubmed central and Scielo. The review applied took into account scientific sources of the years 2015 to the 2020 for builder on the structure of the virus, genome and virulence, besides mechanisms of action of the antimalárics and clinical essays for evidentiary the action antiviral cloroquine/ hidroxicloroquine and mefloquine. The terms of research employed for the obtaining of the information were: COVID-19, SARSCov-2, therapeutic option and pandemic., the research allowed the achievement of 132 articles related with the research, of which were filtered and prioritised by thematic relevance until situating 45 articles with wide relation on the effects of the antimaláric cloroquine/ hidroxicloroquine and mefloquine in the acute respiratory syndrome severe, generated by the SARS- CoV- 2 . 


\section{Development}

\section{Pathogenesis of the infection by SARS-CoV-2}

The SARS-CoV-2 belongs to the gender $\beta$ of the coronavirus $(\mathrm{CoV})$ which are virus wrapped with a genome of positive RNA, pertaining to the family Coronavirus of the order Nidovirals. ${ }^{5}$ His genome is similar to the of the $\mathrm{CoV}$ and contains at least ten frames of reading opened (ORF). ${ }^{6}$ The ORFs of SARS-CoV-2 in a third of the genome encode four structural proteins main: spike (Spike) (S), wrapping (And), nucleocápside $(\mathrm{N})$ and proteins of membrane $(\mathrm{M})$, as well as several proteins accessories with unknown functions that do not participate in the replication viral. ${ }^{6,7}$ Between these proteins, Spike (S), is a glycoprotein transmembrane that forms homotrímers and projects of the surface viral, ${ }^{5}$ it comprises two subunited functional managers of the union to the receptor of the cell guest (subunited S1) and fusion of the virus and the cellular membranes (subunited S2). ${ }^{8}$ On the other hand 16 no structural proteins (nsp1-nsp16) form the complex replicase-transcriptase viral and reorganize the membranes that originate of the reticle endoplasmic rugs (RER) in vesicles of double membrane where produces the replication viral and the transcription (Figure 1). ${ }^{9}$

Although the pathogenesis of COVID-19 today day is object of study, the mechanisms are very similar to the ones of SARS-CoV and MERS-CoV and in fact the symptomatology showed by the patients with COVID-19 as they are: fever, cough no productive, dyspnea, myalgia, fatigue, headcounts of normal leucocytes or diminished and radiographic evidence of pneumonia is similar to the associated with SARS-CoV and MERS-CoV. ${ }^{10,11}$ It has reported that the protein $\mathrm{S}$ game a paper determinant in the entrance of virus in the cells guest. ${ }^{1}$ Being The union of the protein S to ACE2 for the SARS -CoV and DPP4 for MERS-CoV and the back negative regulation of this receptor what contribute to the pulmonary injury during the SARS -CoV and MERS$\mathrm{CoV}^{11,12}$ The union of the virus with the receptors of the cell guest is a determinant in the pathogeny of the infection and also governs the tropism tisular of the virus. ${ }^{13,14}$ The glycoprotein S of SARS-CoV-2 joins to his cellular receptor, ACE2 of the human cells ${ }^{13}$ After the fusion of the membrane, already was directly with the membrane of the cell guest or with the membrane of the endosome, the genome viral of RNA frees in the cytoplasm, and the RNA revisited to allow the translation of the two polyproteíns, the transcription of the RNA subgenómics and the replication of the virus..$^{15}$ After the replication and the synthesis of RNA sub-genomic, the structural proteins virals, $\mathrm{S}$, and $\mathrm{M}$ translate and insert in the reticle endoplásmic (RE). These proteins move along the road secretor to the reticle endoplásmicintermediate compartment of Golgi (ERGIC) ${ }^{16}$ There, the genomes virals encapsulated by the protein $\mathrm{N}$ sprout in the membranes of the ERGIC that contain structural proteins virals, forming virions mature (Figure 2). ${ }^{17}$

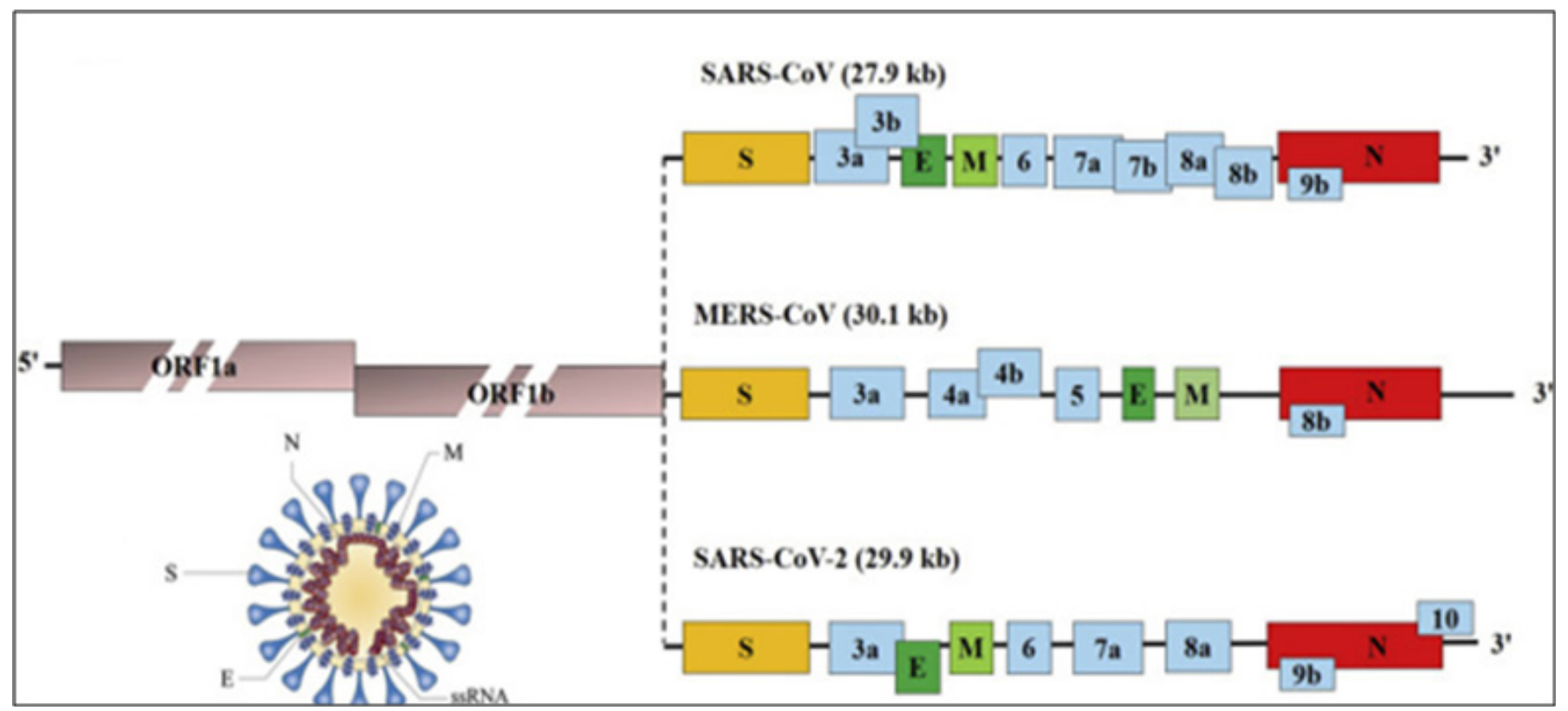

Figure I The coronavirus have a genome of RNA single chain (ssRNA) of positive sense and size 26and32 kb of size. In SARS-CoV, MERS-CoV and SARS-CoV-2, ORFI to / b encode polyproteíns that form the complex of the replicase I transcriptase viral.The others ORF encode four structural proteins main: proteins of spike (S), wrapping (And), nucleocápside $(\mathrm{N})$ and membrane $(\mathrm{M})$, as well as several proteins accesories.

Source: X. Li Et al., Molecular immune pathogenesis and diagnosis of COVID-19, Journal of Pharmaceutical Analysis.

After the assembling, the virions are transported to the cellular surface in vesicles and freed by exocytosis. In several coronavirus, the protein $\mathrm{S}$ that does not assemble in virions happens to the cellular surface where mediates the fusion cell-cell between the cells infected and the adjacent cells no infected. This drives to the training of giant cells multinucleated, what allows that the virus propagate inside an organism infected without being detected or neutralized by specific antibodies of the virus. ${ }^{18,19}$

\section{The antimalarial like alternative of treatment antiviral}

At present it does not exist a medicine or specific treatment for the illness caused by the SARS-CoV-29; for which employs and looks 
for test if the existent drugs, like the antimalárials and some antivirals are effective in the treatment of the illness, the previous due to the fact that develop new specific medicines from zero could take several years. ${ }^{20}$ Inviter, the cloroquine/hidroxicloroquine has showed activity antiviral against virus DNA and RNA, activity that has related mainly to his capacity to affect the entrance of the viruses to the cell guest for being east a step dependent $\mathrm{pH}$ and inhibit the replication viral. ${ }^{21-23}$ unfortunately no always the results have been reproducible in the clinical essays.

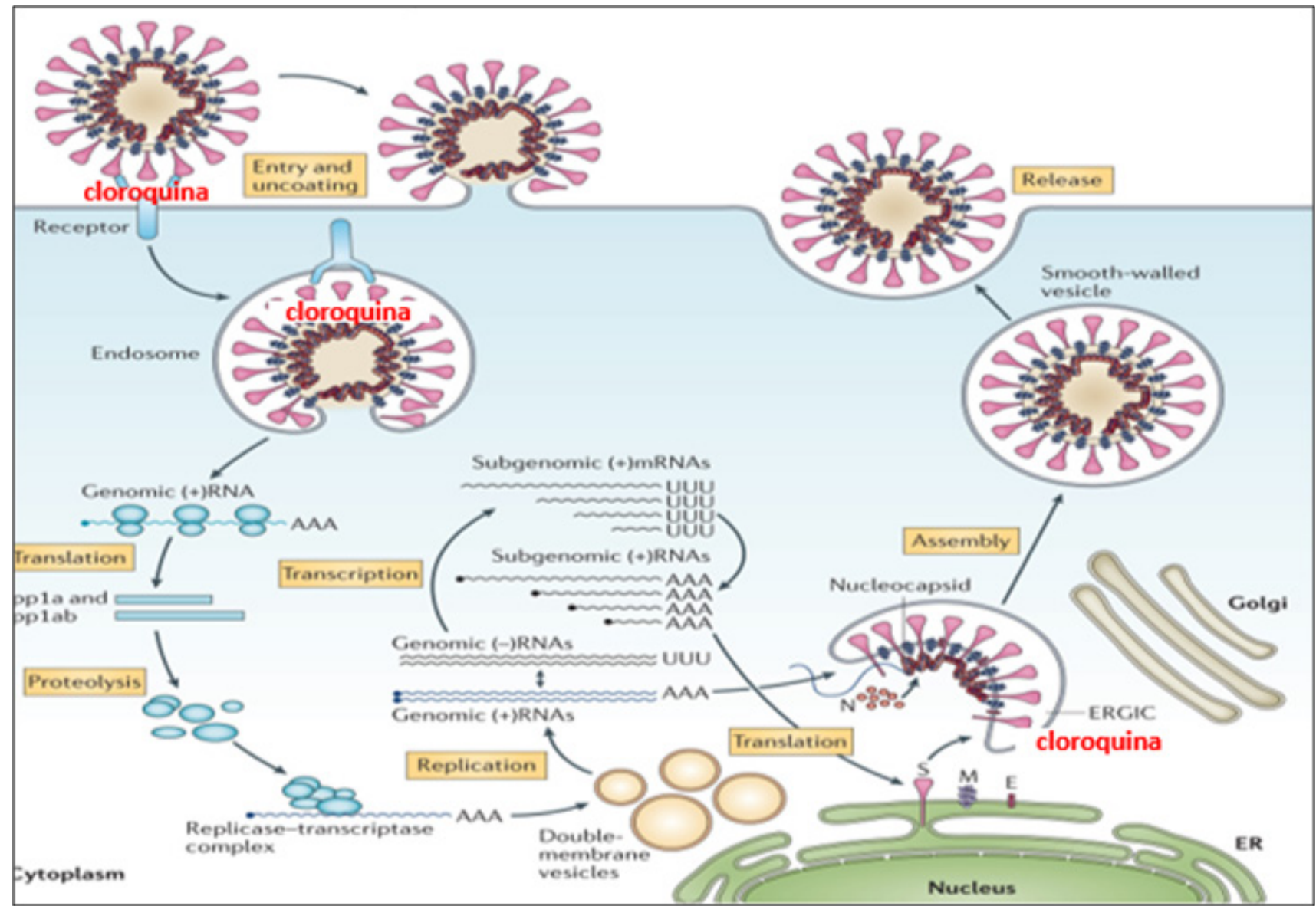

Figure 2 Process of union to the receptor of the human cell, process of replication, assembling and release of the virión from the cell infected and key places of action of the cloroquine/hidroxicloroquine Source: OfWit,And., they Go Doremalen et al.,N.,SARS and MERS: Recent insights into emerging coronaviruses. Nature Reviews Microbiology.

In spite of the studies invitro made by Keyaerts and Masakazu with $\mathrm{HCoV}-\mathrm{OC} 43$ and $\mathrm{HCoV}-229$ respectively to show the therapeutic profits of the inhibition viral by cloroquine the results even are not conclusive and even consider controversial, ${ }^{24,25}$ in front of the absence of better evidence and the situation of public health, authorised the use of cloroquine like line of treatment in the patients with COVID-19 and according to the Chinese authorities report improvement in the symptomatology and images tomográfics in the patients infected by which at present carry out clinical essays to evaluate the cloroquine like a therapy anti-COVID-19. ${ }^{26}$

\section{Activity antiviral of the cloroquine/hidroxicloroquine}

The cloroquine (CQ), is a 4 -aminoquinoline known from 1934. In addition to his known effects antimaláric, the medicine has biochemical properties that they could apply against some infections virales. The cloroquine/ hidroxicloroquine belong to the same molecular family; but in spite of having a farmacocinética similar the clinical indications and the doses toxicas of these drugs differ slightly. ${ }^{23}$ It is characteristic of these drugs the variability interindividual in the absorption, sand distribute widely in the muscular fabric, liver, spleen, kidneys, lungs, blood cells, glands pituitaria and suprarenal and fabrics that contain melanin ,sand metabolizan in the liver and excrete by renal road. ${ }^{27}$ So much the cloroquine like the hidroxicloroquine are feeble bases that affect the sour vesicles that drive to the dysfunction of several enzymes. Extracelular, the cloroquine/hidroxicloroquine is present mainly in a form protonate that, because of his positive load, is unable to cross the membrane plasmática. However, the portion no protonate can increase to the intracellular compartment, where, to his time, proton of way inversely proportional to the $\mathrm{pH}$, in accordance with the law of Henderson-Hasselbach. Once inside, the nitrogen's of the cloroquine (and quinines in general) warn the acidification when absorbing a big quantity of hydrogens that simply interaction with the nitrogen and afterwards the cloroquine loads positively, an ionic interaction that hampers that the endosome acidify. Therefore, the cloroquine goes to have preference by the organelles where the $\mathrm{Ph}$ is low like the endosome, the vesicles of Golgi and the lysosomes. 
The result is a tampon that keeps it to a higher $\mathrm{pH}$ and avoids that it go back the sufficiently sour as to be functional. The enzymes of the organelle cannot work because the group donor will be an ion of hydrogen, disabled the hydrolysis required for the replication of the coronavirus. This means that all type of events in the cell are unable to work of optimum way, including the replication viral. ${ }^{28,29}$

Having In account these characteristics has $\mathrm{n}$ described different mechanisms through the drugs can affect the cycle viral (Figure 2):

A. The cloroquine can inhibit the start of the cycle viral when interfering in the union of the virus with his receptor in the cellular surface. The previous has associated to his capacity of indigo the quinone reductase $2,{ }^{30}$ that are involved in the biosynthesis of the acids siálicos which find presents in the proteins transmembrane cellular and is a compose you critical of the recognition of ligands. This possible interference with the biosynthesis of acid siálico could explain the wide spectrum antiviral of these drugs, since the viruses like the coronavirus human $\mathrm{HCoV}-\mathrm{Or} 43$ and the ortomixovirus use rests of acid siálico like receptors. ${ }^{31}$ It is possible that the cloroquine interfere with the glycosylation of the receptor ACE2, avoiding like this the union of the SARS-CoV-2 to the objective cells. ${ }^{32}$

B. The cloroquine also can interfere with the entrance viral mediated by the endosome dependent of the $\mathrm{pH}$ of the viruses wrapped like the virus Dengue or the virus Chikungunya probably by the inhibition of endocytosis and/or the fast elevation of the $\mathrm{pH}$ endosómico and the cancellation of the fusion virus-endosome, inhibiting like this the training of the car phagosome. ${ }^{33,34}$

C. Blockade of the cycle of replication viral; and absence of a drug antiviral, the virus directs to the compartment lysosome where the low $\mathrm{pH}$, together with the action of the enzymes, allows the release of the nucleic acid infectious and, in several cases, the necessary enzymes for his replication, Sand discovered that the inhibition of the virus of the hepatitis To mediated by cloroquine associates with the elimination of the coating, blocking like this all his cycle of replication. ${ }^{29,35}$

D. The cloroquine also can interfere with the modification postraductional of the proteins virals. These modifications postraduccionales, that involve proteases and glycosyltransferases, occur inside the reticle endoplasmic or the vesicles of the network trans-Golgi and can require a low $\mathrm{pH} .{ }^{36}$ Using the coronavirus no human, showed that the intracellular place of the gemmation of the coronavirus is determined by the location of his proteins $M$ of membrane that accumulate in the complex of Golgi further of the place of the gemmation of the virión, what suggests a possible action of 1 to cloroquine in SARS-CoV-2 in this step of the cycle of replication. ${ }^{37}$

E. In addition to affecting the process of maduration of the virus, the modulation of the $\mathrm{pH}$ by the action of the cloroquine can alter the maduration of the protein viral $\mathrm{M}$ and interfere with the assembling and the training of viriones and the recognition of the antígeno viral by the cells dendríticas, what occurs through a dependent road of the receptor type Toll-like (TLR), that requires acidification endosómica. ${ }^{38}$

F. The cloroquine/hidroxicloroquine also have effect inmunomodulator which is complex and no completemind cleared. Accept That it controls the process of autoinmunity by several roads, inside what stands out his capacity for interfering with the presentation of auto antigens, block the answer of lymphocytes $\mathrm{T}$ induced by antigens, diminish the production of mediators inflammatory and inhibitor the activation of the receptors Toll-like $(\mathrm{TLR})^{39}$ the cloroquine inhibits the phosphorylation (activation) of the protein quinase activated by mitogen p38 (MAPK) in the cells THP-1, as well as the caspasa- $1 .^{40}$

\section{Mefloquine}

The mefloquine is an analogous synthetic of the quinine indicated for the prevention and the treatment of the malaria. As they have registered it several news means is being employed in clinical essays to verify his efficiency and security in the control in the illness COVD-19, but still does not have conclusive results. In spite of the previous also have made multiple studies of his activity antiviral standing out the made by Brickelmaier et al in the year 2009 where showed invitro that this drug inhibits the replication of the DNA viral, of the JCV (virus John Cunningham) after the entrance of the virus to the cell, but is not able to inhibit the entrance of the virus. ${ }^{41}$ During the 2017 the mefloquine was employ to in different essays invitro to test if it was able to block the infection of human cells by virus Zika (ZIKV), but did not obtain conclusive results. ${ }^{42}$ In spite of the existence of diverse clinical essays where has showed the activity antiviral of the mefloquine $e^{43,44}$ it is important to take into account that this medicine is neurotóxic, causes adverse reactions severe neuropsychiatric like anxiety, confusion, convulsions, attacks of panic, nightmares, aggressiveness, agitation, depression, paranoia , cognitive deterioration, psychosis. ${ }^{45}$ Until where knows today day to being object of investigation his effectiveness like medicine for the current pandemic of COVID-19, therefore, his use still is not recommended.

\section{Conclusion}

The activity of the hidroxicloroquine in the viruses is the same that the one of the cloroquine since the mechanism of action of these two molecules is identical. In front of the pandemic suggests the use of hidroxicloroquine or cloroquine in the handle of patients with infection by SARS CoV-2/ COVID-19 that do not have contraindication for his use and does not have to forget the derivative cardiac toxicity to these drugs like cause of mortality, by what the therapy has to be individualized. On the other hand, it does not recommend the use of mefloquine by his effect neurotoxic and association to adverse reactions neuropsychiatric. In the actuality develop of simultaneous way and in multiple international cooperation clinical essays on the efficiency of the at present used drugs, and in spite of the enormous scientific evidence around the drugs studied greater fault compression on the virus and therefore only it remains to recommend preventive measures.

\section{Acknowledgments}

None.

\section{Funding}

None.

\section{Conflicts of interest}

Author declares that there is no conflict of interest. 


\section{References}

1. Peng Zhou, Xing-Lou Yang, Xian-Guang Wang, et al. To pneumonia outbreak associated with to new coronavirus of likely bat origin. Nature. 2020;579(7798):270-273.

2. Alexandra C Walls, Young-Jun Park, M Alejandra Tortorici, et al. Structure, Function, and Antigenicity of the SARS-CoV-2 Spike Glycoprotein. Cell. 2020;180(6):1-12.

3. Mohammad Ammad Ud Din, Leela Krishna Teja Boppana. An update on the 2019-nCoV outbreak. Am J Infect Control. 2020;48(6):713.

4. Di Wu, Tiantian Wu, Qun Liu, et al. The SARS-CoV-2 outbreak: what we know. Int $J$ Infect Dis. 2020;94:44-48.

5. M Alejandra Tortorici, David Veesler. Structural insights into coronavirus entry. Adv Virus Res. 2019;105:93-116.

6. Anthony R Fehr, Stanley Perlman. Coronaviruses: An Overview of Their Replication and Pathogenesis. Methods Mole Biol. 2015;1282:1-23.

7. Berend Jan Bosch, Ruurd van der Zee, Cornelis A M de Haan, et al. The Coronavirus Spike Protein Is to Class I Virus Fusion Protein: Structural and Functional Characterization of the Fusion Core Complex. $J$ Virol vol. 2007;77(16):8801-8811.

8. Canrong Wu, Yang Liu, Yueying Yang, et al. Analysis of therapeutic targets for SARS-CoV-2 and discovery of potential drugs by computational methods. Acta Pharm Sin B. 2020;10(5):766-788.

9. Kèvin Knoops, Marjolein Kikkert, Sjoerd H E van den Worm, et al. SARS-coronavirus replication is supported by to reticulovesicular network of modified endoplasmic reticulum. PLoS Biol. 2008;6(9):e226.

10. Wei Xia, Jianbo Shao, Yu Guo, et al. Clinical and CT features in pediatric patients with COVID-19 infection: Different points from adults. Pediatr Pulmonol. 2020;55(5):1169-1174.

11. Fan $\mathrm{Wu}, \mathrm{Su} \mathrm{Zhao}, \mathrm{Bin} \mathrm{Yu}$, et al. To new coronavirus associated with human respiratory disease in China. Nature. 2020;579(7798):265-269.

12. V Stalin Raj, Huihui Mou, Saskia L Smits. Dipeptidyl peptidase 4 is to functional receptor for the emerging human coronavirus-EMC. Nature. 2013;495(7440):251-254.

13. JH Kuhn, W Li, H Choe, et al. Angiotensin-converting enzyme 2 To functional receptor for SARS coronavirus. Cell Mole Life Sci. 2004;61(21):2738-2743.

14. JK Millet, GR Whittaker, et al. Host cell proteases: Critical determinants of coronavirus tropism and pathogenesis. Virus Res. 2015;202:120-134.

15. Marion Sevajol, Lorenzo Subissi, Etienne Decroly, et al. Insights into RNA synthesis, capping, and proofreading mechanisms of SARScoronavirus. Virus Res. 2014;194:90-99.

16. Cornelis AMde Haan, Peter JM Rottier. Molecular Interactions in the Assembly of Coronaviruses. Adv Virus Animal. 2005;64:165-230.

17. Xiaowei Li, Manman Geng, Yizhao Peng, et al. Molecular immune pathogenesis and diagnosis of COVID-19. J Pharm Annual. 2020;10(2):102-108

18. Stanley Perlman, Jason Netland. Coronaviruses post-SARS: Update on replication and pathogenesis. Nat Rev Microbiol. 2009;7(6):439-450.

19. Emmie de Wit, Neeltje van Doremalen, Darryl Falzarano, et al. SARS and MERS: Recent insights into emerging coronaviruses. Nat Rev Microbiol. 2016;14(8):523-534.

20. Julie Dyall, Christopher M Coleman, Brit J Hart, et al. Repurposing of clinically developed drugs for treatment of Middle East respiratory syndrome coronavirus infection. Antimicrob Agents Chemother. 2014;58(8):4885-4893
21. Kleber Juvenal Silva Farias, Paula Renata Lima Machado, Renato Ferreira de Almeida Junior, et al. Chloroquine interferes with dengue-2 viruses replication in Or937 cells. Microbiol Immunol. 2014;58(6):318326.

22. Tomokazu Mizui, Shunhei Yamashina, Isei Tanida, et al. Inhibition of hepatitis $\mathrm{C}$ virus replication by chloroquine targeting virus-associated autophagy. J Gastroenterol. 2010;45(2):195-203.

23. Andrea Savarino, Johan R Boelaert, Antonio Cassone, et al. Effects of chloroquine on viral infections: An old drug against today's diseases? Lancet Infect Dis. 2003;3(11):722-727.

24. Els Keyaerts, Sandra Li, Leen Vijgen, et al. Antiviral activity of chloroquine against human coronavirus OC43 infection in newborn mice. Antimicrob Agents Chemother. 2009;53(8):3416-3421.

25. Masakazu Kono, Koichiro Tatsumi, Alberto M Imai, et al. Inhibition of human coronavirus 229And infection in human epithelial lung cells (L132) by chloroquine: Involvement of p38 MAPK and ERK. Antiviral Research. 2008;77(2):150-152.

26. ZJHHHXZ Zhi. Multicenter collaboration group of Department of Science and Technology of Guangdong Province and Health Commission of Guangdong Province for chloroquine in the treatment of novel coronavirus pneumonia. Chinese J Tuberc Respir Dis. 2020;43(3):185-188.

27. Álvaro Danza, Diego Graña, Mabel Goñi, et al. Hidroxicloroquina in the treatment of the illnesses autoinmunes sistémicas. Rev Med Chil. 2016;144(2):232-240

28. R. McBride, M They go Zyl, BC Fielding. The coronavirus nucleocapsid is to multifunctional protein. Viruses. 2014;6(8):2991-3018.

29. Martin J Vincent, Eric Bergeron, Suzanne Benjannet, et al. Chloroquine is to potent inhibitor of SARS coronavirus infection and spread. Virol J. 2005;2:69.

30. Jesse J Kwiek, Timothy A J Haystead, Johannes Rudolph, et al. Kinetic Mechanism of Quinone Oxidoreductase 2 and Its Inhibition by the Antimalarial Quinolines. Biochemistry. 2004;43(15):4538-4547.

31. Sigvard Olofsson, Urban Kumlin, Ken Dimock, et al. Avian influenza and sialic acid receptors: dwell than meets the eye? Lancet Infect Dis. 2005;5(3):184-188

32. Christian A Devaux, Jean-Marc Rolain, Philippe Colson, et al. New insights on the antiviral effects of chloroquine against coronavirus: what to expect for COVID-19? Int J Antimicrob Agents. 2020;55(5):105938.

33. Vianney Tricou, Nguyet Nguyen Minh, Toi Pham Van, et al. To randomized controlled trial of chloroquine for the treatment of dengue in vietnamese adults. PLoS Negl Trop Dis. 2010;4(8):1-13.

34. Bernard Gay, Eric Bernard, Maxime Solignat, et al. PH-dependent entry of chikungunya virus into Aedes albopictus cells. Infect Genet Evol. 2012;12(6):1275-1281.

35. Hongliang Wang, Peng Yang, Kangtai Liu, et al. SARS coronavirus entry into host cells through to novel clathrin- and caveolae-independent endocytic pathway. Cell Animal. 2008;18(2):290-301.

36. A Savarino, L Gennero, K Sperber, et al. The anti-HIV-1 activity of chloroquine. J Clin Virol. 2001;20(3):131-135.

37. Anabelle Perrier, Ariane Bonnin, Lowiese Desmarets, et al. The C-terminal domain of the MERS coronavirusMprotein contains to transGolgi network localization signal. J Biol Chem. 2019;294(39):1440614421 .

38. Philippe Colson, Jean-Marc Rolain, Jean-Christophe Lagier, et al. Chloroquine and hydroxychloroquine ace available weapons to fight COVID-19. Int J Antimicrob Agents. 2020;105932. 
39. Nathalie Costedoat-Chalumeau, Bertrand Dunogué, Nathalie Morel, et al. Hydroxychloroquine: To multifaceted treatment in lupus. Presse Med. 2014;43(6 Pt 2):e167-e180.

40. Michael Seitz, Jean Valbracht, Jacqueline Quach, et al. Gold Sodium Thiomalate and Chloroquine Inhibit Cytokine Production in Monocytic THP-1 Cells Through Distinct Transcriptional and Posttranslational Mechanisms. J Clin Immunol. 2003;23(6):477-484.

41. Margot Brickelmaier, Alexey Lugovskoy, Ramya Kartikeyan, et al. Identification and characterization of mefloquine efficacy against JC virus in vitro. Antimicrob Agents Chemother. 2009;53(5):1840-1849.

42. Nicholas J Barrows, Rafael K Campos, Steven T Powell, et al. To screen of FDA-approved drugs for inhibitors of Zika virus infection. Cell Host Microbe. 2016;20(2):259-270.
43. Anuradha Balasubramanian, Tadahisa Teramoto, Amol A Kulkarni, et al. Antiviral activities of selected antimalarials against dengue virus type 2 and Zika virus. Antiviral Res. 2017;137:141-150.

44. Wei Sun, Shihua He, Carles Martínez-Romero, et al. Synergistic drug combination effectively blocks Ebola virus infection. Physiol Behav. 2017;176(12):139-148.

45. RL Nevin. To serious nightmare: psychiatric and neurologic adverse reactions to mefloquine plough serious adverse reactions. Pharmacol Animal Perspect. 2017;5(4):e00328. 